\title{
Mercados e Racionalidades: a perspectiva de Alberto Guerreiro Ramos e Cornelius Castoriadis
}

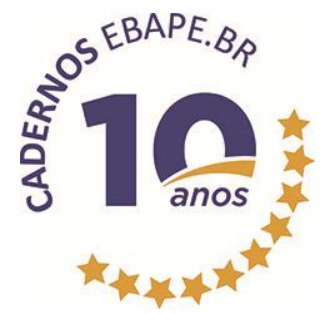

\section{Markets and Rationalities: the perspective of Alberto Guerreiro Ramos and Cornelius Castoriadis}

\author{
Manoel Fernandes Nery ${ }^{1}$ \\ Daniel Lanna Peixoto ${ }^{2}$
}

\begin{abstract}
Resumo
Mercados e racionalidades são duas categorias das Ciências Sociais bastante discutidas na academia. Considera-se Max Weber um dos pioneiros no estudo da categoria racionalidades, da qual teria se originado grande parte das interpretações dominantes nas Ciências Sociais, em particular da Sociologia. Os autores que descrevem o mercado enfatizam diferentes aspectos, e os relatos sobre seu aparecimento histórico são também divergentes. Não existe, portanto, nas Ciências Sociais, uma interpretação única sobre as funções e a historicidade do mercado, bem como não há unanimidade em relação às formas de racionalidades dominantes. Este ensaio teórico traz a perspectiva de dois autores sobre mercados e racionalidades, sem a intenção de absolutizar seu pensamento ou limitar suas contribuições aos temas. Ramos (1981) concebe a razão como uma força inerente ao indivíduo, a qual denomina razão substantiva, assinalando que, com Thomas Hobbes, a razão configura um cálculo utilitário de consequências. Adicionalmente, Ramos (1981) vê o mercado como uma ameaça à liberdade e autonomia dos indivíduos. Para Castoriadis (1992b, 1996, 1999b), a razão está presente em um coletivo social anônimo, sendo homem e sociedade inseparáveis do contexto sócio-histórico. Já o mercado, bem ou mal, funciona, apesar da manipulação dos consumidores e da violência contra os trabalhadores. Em comum, os autores defendem a liberdade e a autonomia dos indivíduos. Conclui-se o ensaio corroborando a visão de Alves (2007), pois as elucidações apresentadas ao longo do texto indicam que as divergências não estão nas teorias e nos métodos, mas na natureza do objeto estudado.
\end{abstract}

Palavras-chave: Mercado. Sociologia. Racionalidades. Desenvolvimento. Autonomia.

\begin{abstract}
Markets and rationalities are two categories of Social Science much debated in the academy. Max Weber is regarded as a pioneer in the study of the category rationalities, from which a large part of the dominant interpretations in Social Science originated, especially those in Sociology. The authors describing the market emphasize different aspects, and the reports about its historic emergence are also divergent. There is not, therefore, in Social Science, a unique

Artigo submetido em 29 de abril de 2013 e aceito para publicação em 05 de dezembro de 2013.

${ }^{1}$ Mestre em Administração pela Universidade Federal do Espírito Santo - UFES; Administrador na UFES. Endereço: Av. Antônio Gil Veloso, 440 - 804 - Praia da Costa, CEP 29101-010, Vila Velha - ES, Brasil. E-mail: manoelfnery@gmail.com

2 Doutorando em Administração pela Universidade Federal de Minas Gerais - UFMG; Professor do Instituto Federal de Educação, Ciência e Tecnologia do Espírito Santo IFES. Endereço: Rua Elizabeth Minete Perim, S/N, São Rafael, CEP 29375-000, Venda Nova do Imigrante - ES, Brasil. E-mail: lannapeixoto@gmail.com
\end{abstract}


interpretation of the functions and the historicity of the market, as well as there is no unanimity with regard to the dominant rationality ways. This theoretical essay brings the perspective of two authors on markets and rationalities, with no intent of absolutizing their thought or restricting their contributions to the themes. Ramos (1981) conceives reason as a force inherent to the individual, which he names substantive reason, pointing out that, with Thomas Hobbes, reason configures a utilitarian calculation of consequences. Additionally, Ramos (1981) sees the markets as a threat to freedom and individuals' autonomy. According to Castoriadis (1992b, 1996, 1999b), reason is present in an anonymous social collective, man and society are inseparable from the socio-historical context. In turn, the market, good or bad, works, although manipulating consumers and exerting violence against workers. In common, the authors advocate for freedom and individuals' autonomy. We conclude the essay corroborating the view of Alves (2007), as the clarifications presented throughout the text indicate that divergences are not in the theories and methods, but in the nature of the object under study.

Keywords: Market. Sociology. Rationalities. Development. Autonomy.

\section{Introdução}

Guerreiro Ramos e Cornelius Castoriadis são dois autores que trazem contribuições teóricas bastante expressivas para o campo das ciências sociais. Suas contribuições teóricas não se restringem aos temas aqui tratados, racionalidade e mercado. Partindo de perspectivas diferentes, sobretudo em relação ao indivíduo, as teses dos autores são, na essência, complementares. Castoriadis (1992a), quando fala da autonomia dos seres humanos, referindo-se a indivíduos, não vê autonomia fora de uma coletividade, enquanto para Ramos (1981) a sociedade não gera padrões de existência substantiva em seu conjunto.

Ambos, contudo, quando perpassam os temas da racionalidade e do mercado imbricados no contexto das ciências sociais, convergem para o pensamento de que a razão se tornou, por excelência, um cálculo utilitário de consequências, expressa na matematização do mundo, e a ideologia do progresso e do desenvolvimento não trouxe para os indivíduos a autonomia e as liberdades esperadas, que os autores defendem de forma veemente. Na defesa desses pressupostos, a autonomia e a liberdade dos indivíduos, está a convicção de que a dimensão econômica é apenas incidental na existência humana e os indivíduos não funcionam tentando maximizar/minimizar suas utilidades e desutilidades, seus benefícios e custos, como pressupõem a racionalidade econômica dominante e a ideologia de mercado. Estimulantes, as perspectivas desses autores são apresentadas ao longo do texto.

Alberto Guerreiros Ramos, cientista social, é considerado, por suas ideias e posições, um crítico das ciências sociais em geral e, em particular, da teoria geral das organizações, sendo tido como um dos pioneiros dos estudos críticos em administração no Brasil. Defende a necessidade de uma "nova ciência das organizações" (RAMOS, 1981). Baseado no conceito de delimitação dos sistemas sociais, apresenta um modelo multicêntrico de análise dos sistemas sociais e do desenho organizacional.

A teoria das organizações incorporou modelos e conceitos estranhos a seu domínio, tornando-se acrítica, pois aceita o estado dos negócios humanos na sociedade, centrada no mercado, como uma premissa definitiva. A teoria das organizações não examinou em termos críticos a epistemologia inerente a esse sistema de mercado. O autor propõe a reformulação da teoria sob novos fundamentos epistemológicos (RAMOS, 1981).

Cornelius Castoriadis, filósofo e economista, é um crítico da Filosofia, da Ontologia e da Economia. De acordo com ele, a Filosofia ignorou o social-histórico, tanto como domínio próprio e modo de ser quanto como fundamento e o meio de todo pensamento, o que pode ser constatado pela forma como a Filosofia, de Platão a Heidegger, estruturou seu domínio. Referindo-se à Ontologia, ressalta que fatos fundamentais relativos ao Ser, ao Tempo e à Criação foram encobertos pela Ontologia tradicional, porque essa Ontologia sempre procedeu, em sua vertente principal, por meio da hipercategoria fundamental da determinidade. A Economia recebeu críticas por tentar ser o reino e o paradigma da "racionalidade" e precisão nos assuntos humanos (CASTORIADIS, 1987a; 1992b; 1999a). 
Castoriadis (1996) questiona também a ideologia de uma "racionalidade" do capitalismo, ressaltando a necessidade de se relativizar e discutir essa "racionalidade". A "legitimação" do capitalismo, segundo ele, se dá muito mais pela glorificação dos economistas do que efetivamente por seus resultados.

Em relação ao sujeito, em contraposição àqueles que consideram possível a previsibilidade de comportamento, Castoriadis (1999b) reconhece a especificidade da subjetividade e a complexidade do processo de socialização dos indivíduos. Assegura que a psique forçada a abandonar seu sentido original "monádico" em favor do sentido participado, fornecido pela sociedade, nunca o faz completamente, subordinando apenas parcialmente suas criações e seus impulsos às exigências da vida social.

No Posfácio da obra Sujeito e verdade no mundo social histórico (CASTORIADIS, 2007), o autor traz evidências de que por incompreensão, por seu estilo intelectual, pela forma de apresentação de suas ideias e, notadamente, pela relação com seus contemporâneos, suas obras não alcançaram o devido eco e a dimensão esperada.

O tempo, para ele, é sempre dotado de significação (CASTORIADIS, 1992b). O tempo imaginário é o tempo significativo e o da significação. Na verdade, tempo é criação. Nessa linha de raciocínio, o autor assinala que a sociedade se cria - se institui - ao longo de duas dimensões tecidas juntamente: a dimensão conjuntista identitária (conídica) e a dimensão propriamente imaginária, ou poiética. Toda sociedade é uma construção, uma constituição, uma criação de mundo, de seu próprio mundo. A sociedade é autocriação. Sua própria identidade nada mais é que esse "sistema de interpretação", esse mundo que ela cria.

As significações sociais fazem parte da forma de ser da própria sociedade. A sociedade resulta das contribuições de um "coletivo anônimo". O homem e a sociedade são inseparáveis de seus contextos - o contexto social-histórico (CASTORIADIS, 1999a; 1999b).

As informações precedentes têm a finalidade de esboçar as principais linhas de pensamento da obra desses autores. Ressalte-se, entretanto, que este ensaio teórico se propõe apenas a realizar uma incursão parcial na vasta contribuição teórica por eles desenvolvida, bem como promover um diálogo sobre mercados e racionalidades na visão dos dois autores. Indicam-se, ainda, os pontos que os aproximam e os que os separam em relação ao assunto abordado e, por último, faz-se uma análise e tecem-se considerações sobre o pensamento dos autores.

\section{O mercado em Guerreiro Ramos}

Ramos (1981) argumenta que a ciência social tem como característica particular o sistema de mercado e que a teoria da organização tem como fundamento epistemológico a sociedade centrada no mercado. Sob essas premissas desenvolveram-se as estruturas e as relações sociais, as estruturas e as comunicações organizacionais. O mercado tornou-se, então, a força modeladora da sociedade e o paradigma para a organização de toda a vida humana.

O pensamento liberal dominante faz uma defesa intransigente do livre mercado, no qual, segundo essa visão, ocorreria um equilíbrio entre a oferta e a procura de bens. Para Adam Smith, o mercado alcança esse equilíbrio por meio de uma "mão invisível" que o regula, tornando possível a realização dos diversos interesses. Ramos (1981) critica tal assertiva, e afirma que Adam Smith agiu como fundamentalista ao exaltar o mercado como um ethos da existência humana.

Para Ramos (1981) a sociedade centrada no mercado caracteriza-se por uma síndrome comportamentalista que ele define como uma disposição socialmente condicionada que afeta a vida das pessoas, na medida em que confundem as regras e normas de operação peculiares a sistemas sociais episódicos, nesse caso o mercado, com regras e normas de sua conduta como um todo. A síndrome comportamentalista resulta de um 
esforço histórico sem precedentes para modelar uma ordem social de acordo com critérios de economicidade. $\mathrm{Na}$ mesma obra, Ramos acrescenta que há uma identificação da natureza humana com a síndrome comportamentalista, ocorrendo também uma identificação entre a comunicação humana e a comunicação instrumental. $\mathrm{O}$ autor descreve os traços principais dessa sociedade, os quais inspiram a teoria da organização: a fluidez da individualidade, o perspectivismo, o formalismo e o operacionalismo. Esses traços caracterizam as condutas e as ações das pessoas na sociedade centrada no mercado.

Ainda na mesma obra (1981), Ramos considera que os últimos três séculos têm sido marcados por uma experiência histórica que tenta criar um tipo nunca visto de vida humana associada, ordenada e sancionada por processos autorreguladores do mercado. Uma experiência bem-sucedida, pois o mercado e seu caráter utilitário tornaram-se forças históricas e sociais, institucionalizadas em larga escala, além de demonstrarem ser altamente convenientes para a escalada e a exploração dos processos da natureza e para a maximização da inventiva e das capacidades humanas de produção.

Ao iniciar uma discussão analítica sobre os traços inerentes à sociedade centrada no mercado, Ramos (1981) sustenta que a fluidez da individualidade não pode ser inteiramente explicada sem que se vincule esse fenômeno à forma de representação por meio da qual as sociedades capitalistas legitimam-se a si mesmas. Essa fluidez seria, portanto, atributo das pessoas em sociedades cuja existência não se fundamenta sobre princípios meta-históricos. A sociedade moderna, diferentemente, centrada no mercado, não se reconhece como miniatura de um cosmo maior, mas como um contrato amplo entre seres humanos. Assim, a conduta humana se conforma a critérios utilitários que estimulam a fluidez da individualidade. O homem moderno é, na verdade, uma fluida criatura calculista que se comporta essencialmente de acordo com regras objetivas de conveniência (RAMOS, 1981).

"O indivíduo ganhou melhoria material em sua vida e pagou por ela com a perda do seu senso pessoal de auto-orientação" (RAMOS, 1981, p. 52). A isenção do mercado da regulação política, ao mesmo tempo, deu origem a um tipo de vida humana associada, ordenada apenas pela interação dos interesses individuais (para a autopreservação), isto é, uma sociedade em que o puro cálculo das consequências substituiu o senso comum. Essa forma de cultivo da individualidade só pode resultar em narcisismo.

Prosseguindo sua análise, o autor assegura que, ao interpretar a sociedade como um sistema de regras contratadas, o indivíduo é levado a compreender que tanto sua conduta quanto a dos outros são afetadas por uma perspectiva. A perspectiva, embora sendo um ingrediente da conduta humana em qualquer sociedade, ganha destaque na sociedade moderna. A sociedade moderna gera um tipo particular de conduta. Nela o indivíduo só tem que levar em conta as conveniências exteriores, os pontos de vista alheios e os propósitos em jogo. O perspectivismo, acrescenta, constitui uma feição da vida diária de um grande número de pessoas envolvidas em atividades proporcionadas pelo sistema de mercado. Na realidade, o mercado é a força subjacente geradora da visão perspectivista da vida humana associada (RAMOS, 1981).

O formalismo é um terceiro aspecto dos fundamentos que inspiram a teoria da organização e a sociedade centrada no mercado. O termo, geralmente empregado pelos historiadores das artes, refere-se a uma característica psicológica particular da sociedade ocidental, no início do período capitalista. O formalismo é útil como uma categoria explicativa da conduta humana que se tornou externamente orientada. Tornou-se um traço normal da vida cotidiana, na qual a observância das regras substitui a preocupação pelos padrões éticos substantivos e os indivíduos sujeitam-se aos imperativos externos, segundo os quais é produzida a vida social.

O último dos traços analisados, o operacionalismo, pode ser qualificado como operacionalismo positivista. O operacionalismo positivista considera que só existe sabedoria por critérios de exatidão. Dessa perspectiva, tudo aquilo que é conceituado como forma na metafísica, como virtude na moral, como beleza estética, não é dado à percepção humana da mesma maneira que tamanho, forma, extensão e quantidade de objetos. Todavia, os julgamentos que dizem que um indivíduo é bom e que uma obra de arte é bela, significam que virtude e beleza são objetos reais de uma espécie determinada, não apreendida diretamente pela percepção 
sensorial imediata. Na raiz do operacionalismo está o interesse em lidar com problemas práticos do mundo. O operacionalismo positivista é permeado por uma orientação controladora de mundo (RAMOS, 1981).

Os traços da síndrome comportamentalista constituem um credo não enunciado de instituições e organizações que funcionam na sociedade centrada no mercado. Ramos (1981) assegura que o objetivo final do sistema de mercado seria transformar a produção numa atividade científica e prover a sociedade de capacidades de processamento de altas taxas de produtividade, simultaneamente liberando os homens do labor. Na consecução desse objetivo, a sociedade de mercado precisa usar o homem como um fator de produção despersonalizado. A deformação do ser humano imposta por essa transição tem sido o preço psicológico pago pela criação da logística da abundância de bens primordiais para todos. Essa é a grande transformação a ser creditada ao sistema de mercado. O mercado ocupou os espaços reservados aos sistemas sociais.

Essa perspectiva leva Ramos (1981) a pensar o mercado, delimitado, constituindo apenas um enclave do sistema social. O sistema de mercado não deve funcionar em bases puramente técnicas e econômicas. $\mathrm{O}$ autor compartilha da ideia de que a motivação econômica não deve ser o principal traço do ser humano e que o mercado não deve se tornar a principal categoria de ordenação, avaliação e desenho das estruturas sociais. Deixado a sua própria dinâmica, o mercado trabalha contra a constituição da vida humana associada. Nesse contexto, a sociedade é o próprio mercado amplificado (RAMOS, 1981).

\section{O mercado em Castoriadis}

O mercado é incluído como elemento de análise do capitalismo em determinado momento, e não desde sua origem. Um mecanismo institucional da mais alta antiguidade, transformado, desembaraçado, livre de qualquer entrave, e estendido gradualmente a todas as esferas da vida social. Segundo o autor, o mercado não é, nunca foi e jamais será, por mais duradouro que seja o sistema capitalista, um mercado "perfeito" nem verdadeiramente concorrencial no sentido atribuído pelos manuais de economia política (CASTORIADIS, 1996).

O mercado sempre foi caracterizado por intervenções do Estado, coalizões de capitalistas, retenção da informação, manipulação dos consumidores e violência aberta ou camuflada contra os trabalhadores.

Ainda segundo Castoriadis (1996), o mercado pouco difere de uma selva moderadamente selvagem, e, como em toda selva, os mais aptos a sobreviver sobrevivem, exceto quando a aptidão para a sobrevivência não coincide com algum ótimo social, ou mesmo com o máximo de uma produção entravada pela concentração do capital, pelos oligopólios e monopólios, isso sem falar das alocações irracionais de recursos, das capacidades não empregadas e do conflito permanente em torno da produção nos locais de trabalho. Nesse mercado decide-se aquilo que é um produto e como esse produto será avaliado, assim como quais serão e de quanto serão os custos.

O liberalismo econômico e as virtudes da livre concorrência dão o tom do funcionamento do mercado, que não deveria somente produzir novas mercadorias - mas é mercadoria que as pessoas querem. Enquanto as pessoas desejarem acumular "bugingangas", acumulação cada vez mais aleatória, da qual poderão um dia se saturar ou não, a situação não mudará. $\mathrm{O}$ autor reconhece, porém, que com altos e baixos, booms e quebras, o mercado bem ou mal funciona dentro de seus limites e segundo suas finalidades (CASTORIADIS, 1987b; 1996).

\section{A racionalidade em Guerreiro Ramos}

De acordo com Bresser-Pereira (1991), o ato racional é aquele adotado de acordo com a razão. O racionalismo corresponderia então à crença ilimitada na razão humana. 
No pensamento de Ramos (1981), a concepção de razão recebe uma relativa influência dos filósofos gregos, sobretudo Aristóteles e Platão, além de Max Weber, Karl Mannheim e dos teóricos críticos da Escola de Frankfurt.

Ramos (1981), baseado nas contribuições desses filósofos, afirma que todos os homens são guiados por uma razão substantiva em qualquer momento e em qualquer lugar, e que essa razão não deve ser considerada coincidente com padrões particulares de qualquer sociedade determinada. A racionalidade, no sentido substantivo, nunca poderá ser um atributo definitivo da sociedade, pois é diretamente apreendida pela consciência humana, não pela mediação social. Em Platão e Aristóteles há um indissolúvel dualismo entre razão e sociedade, ele próprio constituindo a condição prévia da liberdade. A razão pode ser assim compreendida como uma virtude do indivíduo, e não uma característica da sociedade.

Pela deformação das relações que os indivíduos estabelecem na sociedade moderna, torna-se possível compreender a racionalidade que se desenvolve e que se torna característica das ciências sociais e da teoria da organização.

No sentido clássico, a razão era entendida como força ativa na psique humana que habilitava o indivíduo a distinguir entre o bem e o mal, entre o conhecimento falso e o verdadeiro, e assim ordenar sua vida pessoal e social. Mais ainda, a existência da razão na psique humana era encarada como uma realidade que resistia a sua própria redução a fenômeno histórico e social (RAMOS, 1981).

Começa com Thomas Hobbes, afirma Ramos (1981), a tentativa de despojar a razão de qualquer papel normativo no domínio da construção teórica e da vida humana associada. Hobbes define a razão como uma capacidade que o indivíduo adquire "pelo esforço" e que o habilita simplesmente a fazer o "cálculo utilitário de consequências". Esse processo de deturpação da razão continua com Adam Smith, que procura harmonizar o termo com critérios de economicidade.

Tais constatações levam Ramos (1981) a asseverar que de Hobbes a Adam Smith e aos modernos cientistas sociais em geral, paixões, instintos, interesses e a simples motivação substituíram a razão como referência para a compreensão e a ordenação da vida humana associada. Sob a influência do Iluminismo, de Turgot a Marx, a história substituiu o homem como portador da razão. A palavra razão, em seu sentido normativo, dificilmente poderia ser posta de lado, por força de seu caráter central na vida humana.

A racionalidade, segundo Ramos (1981), também foi uma das preocupações centrais da Escola de Frankfurt. Seus principais representantes afirmam que na sociedade moderna a racionalidade se transformou em um instrumento disfarçado de perpetuação da repressão social, em vez de ser sinônimo de razão verdadeira. Pretendem seus representantes restabelecer o papel da razão como uma categoria ética e, portanto, como elemento de referência para uma teoria crítica da sociedade.

Assegura Ramos (1981) que no contexto da teoria da organização tem prevalecido um conceito de racionalidade instrumental, inerente à ciência social dominante no Ocidente. Nessa perspectiva, a linguagem distorcida tornou-se normal. Acrescenta, ainda, que o conceito de racionalidade predominante na vigente teoria organizacional parece afetado por fortes implicações ideológicas, conduzindo à ideia de que o comportamento econômico constitui totalidade da natureza humana. Uma racionalidade permeada pelo conhecimento absoluto de consequências.

A atual teoria da organização não faz distinção entre a racionalidade substantiva e a racionalidade instrumental, bem como entre o significado substantivo e o significado formal da organização. Acrescenta, contudo, que o lugar adequado da razão é a psique humana, e que esta deve ser considerada o ponto de referência para a ordenação da vida social, tanto quanto para a conceituação da ciência social em geral, da qual o estudo sistemático da organização constitui domínio particular. Uma teoria da vida humana associada é substantiva quando a razão, em seu sentido substantivo, é sua principal categoria de análise (RAMOS, 1981). 
Ramos (1981) propõe uma distinção entre comportamento e ação, para esclarecer o reducionismo psicológico da atual teoria da organização. Comportamento seria então uma conduta que se baseia na racionalidade funcional ou na estimativa utilitária das consequências. Sua categoria mais importante é a conveniência. Consequentemente, o comportamento é desprovido de conteúdo ético de validade geral. Em contraposição, a ação é própria de um agente que delibera sobre coisas porque está consciente de suas finalidades intrínsecas. Pelo reconhecimento dessas finalidades, a ação constitui uma forma ética de conduta. Os seres humanos são levados a agir, tomar decisões e fazer escolhas porque causas finais, e não apenas causas eficientes, influem no mundo em geral. Assim, a ação baseia-se na estimativa utilitária das consequências, quando muito apenas por acidente. O comportamento é um tipo de conduta ditada por imperativos exteriores, enquanto a razão resulta das deliberações dos indivíduos em busca da configuração ética, substantiva, de sua vida associada.

Horkheimer (1947, p. 187, apud RAMOS, 1981) afirma: “A denúncia daquilo que é hoje chamado de razão é o maior serviço que a razão pode prestar".

\section{A racionalidade em Castoriadis}

A ideia de racionalidade em Castoriadis, embora perpasse a compreensão do indivíduo, da sociedade e seu desenvolvimento, dos artefatos e instituições que caracterizam essa sociedade, implica que tempo é criação e que cada sociedade é criação dela mesma: autocriação; criação que não poder ser explicada, mas elucidada (CASTORIADIS, 1999a).

A historicidade da racionalidade, segundo Castoriadis (1987b), citando Descartes, pode remontar ao século XIV. Esse é o ponto de convergência entre o nascimento e a expansão da burguesia, o interesse obsessivo e crescente pelas invenções e descobertas, a progressiva dissolução da representação medieval do mundo e da sociedade, a Reforma, a passagem "do mundo fechado ao Universo infinito", a matematização das ciências, a perspectiva de um "progresso indefinido do conhecimento" e a ideia de que o emprego apropriado da razão é a condição necessária e suficiente para que nos tornemos "senhores e possuidores da natureza".

A razão, os pressupostos de desenvolvimento e a economia, paradigma de "racionalidade" nos assuntos humanos, são, portanto, apenas alguns dos termos que se podem utilizar para designar o complexo de ideias e de concepções ocidentais que em sua maior parte permanecem não conscientes tanto para os políticos como para os teóricos. Concebidos como ideologias, mas também, num nível mais profundo, como significações imaginárias sociais, elas eram e continuam sendo consubstanciadas em um grupo de "postulados" (teóricos e práticos) como: a onipotência virtual da técnica, que torna real o progresso; a ilusão do pleno domínio científico; e o pensamento dominante de que o homem e a sociedade estão inexoravelmente predestinados ao crescimento e ao progresso (CASTORIADIS, 1987b).

Nos termos de Castoriadis (1987b), desenvolvimento e racionalidade legitimam o preço que os seres humanos devem pagar pelo crescimento: interação destrutiva e cumulativa dos efeitos da industrialização; reações ambientais que continuam, para além de determinado ponto, desconhecidas e imprevisíveis, que poderiam desembocar em uma avalanche catastrófica final; derretimento das calotas polares; destruição de barreira de corais; e chuva ácida. São consequências virtuais ou efetivas do crescimento e da industrialização desenfreada.

Essa perspectiva corresponde também à dimensão capitalista das sociedades modernas, cujo pretenso domínio da racionalidade levaria a maior autonomia individual e social; aumento da liberdade individual e coletiva; e maior domínio da pesquisa, que corresponde ao projeto democrático, libertador e revolucionário que não se concretizou, levando, de fato, a uma sociedade antinômica (CASTORIADIS, 2002). 
Assim concebida, Castoriadis (1999 a) afirma que a razão não absorveu uma grande lição de humildade quando, mais que visar à emancipação, passa a pretender o controle ilimitado sobre a natureza, sobre as coisas, sobre os seres. Cada vez que uma sociedade recorre a forças extrassociais e supra-humanas para explicar sua própria instituição - a História, a Natureza, a Razão -, oculta o imaginário social instituinte, ou seja, o poder de criação coletivo e anônimo.

A razão assume também o papel de fundamento inabalável quando a Filosofia ocupa o lugar da tradição e da religião como fonte de formulação categórica da significação de mundo. A razão que entra em cena, de acordo com categorias ontológicas, não é, segundo Castoriadis (1999a), a razão existente em um coletivo social anônimo, mas sim em indivíduos substanciais, nas ideias ou nos sujeitos. Daí o autor acrescentar que o entendimento e a razão são socialmente instituídos, ainda que essa instituição se apoie em possibilidades e tendências intrínsecas da psique humana.

Castoriadis (1999a), em observações sobre Freud a respeito do indivíduo, ressalta que nem a racionalidade implica a consciência, uma vez que todo predador age racionalmente, nem a consciência implicada racionalidade, como o demonstra a mais sumária observação do comportamento humano, individual e coletivo. Acrescenta que não se poderia associar a atividade do conhecimento ao outro "instinto", o da conservação, ele também universal no vivente, sequer relacioná-lo a uma "racionalidade" geneticamente superior do humano, pois esta só poderia conduzir, no melhor dos casos, ao desenvolvimento de um saber puramente funcional e instrumental, submetido à satisfação de "necessidades" perpetuamente idênticas.

Na compreensão da "razão moderna", em que analisa o conceito weberiano de razão, Castoriadis (1992a) admite que um agir motivado por fins que nos são estranhos, ou seja, cujo emprego se afasta da racionalidade dos meios atendendo aos fins, pode, de fato, ser tido como uma racionalidade instrumental. Reconhece ainda que a causalidade significa a regularidade de uma consecução, cuja necessidade é expressa por uma lei universal. Nessa dimensão se encontram, assim, a racionalidade e a inteligibilidade. O fim último das pesquisas de Weber, contudo, seria reduzir os fenômenos estudados aos efeitos dos atos e comportamentos de indivíduos. Ressalta Castoriadis (1992a) que os comportamentos humanos não são, pelos menos parcialmente, pelos menos virtualmente, compreensíveis.

Segundo Castoriadis (1992a), a socialização dos indivíduos, processo ele próprio socialmente instituído e a cada vez diferentemente, abre acesso a um mundo de significações imaginárias sociais. E essas significações não são evidentemente redutíveis à "racionalidade", qualquer que seja a extensão dada ao sentido do termo. O autor ressalta que a incomparabilidade ou incomensurabilidade dos "valores" e dos "fins" últimos do "agir social dos homens" tem por referência verdadeira a "alteridade" dos diferentes mundos social-históricos e das significações imaginárias que os animam. Dessa forma, quanto mais o agir dos homens é motivado, em última análise, pela adesão a "valores últimos", irredutíveis uns aos outros, tanto mais a análise "científica" deve se restringir à racionalidade instrumental como único terreno sólido de pesquisa; e quanto mais se postula que a "racionalidade" é o horizonte último da compreensão, tanto mais os "valores últimos" das diferentes culturas tornam-se de fato inacessíveis, e a compreensão do mundo social-histórico se encontra reduzida à reconstituição de alguns fragmentos ou dimensões instrumentalmente racionais do agir.

No mundo atual, a racionalidade instrumental dos seres humanos é, cada vez mais, socialmente instituída e imposta. Nesse quadro, não há como evitar o crescimento de um individualismo racionalista (CASTORIADIS, 1992a).

Afirma Castoriadis (1992a) que a unidade profunda da razão se manifesta numa diversidade fenomenal, daí a dificuldade de explicar como ordená-las racionalmente. A surdez empedernida das diversas variantes do racionalismo contemporâneo, diante dessas questões elementares e ao mesmo tempo inevitáveis, tem representado menos uma etapa da história do pensamento e mais uma regressão de natureza ideológica. 


\section{Pontos de convergência entre Cornelius Castoriadis e Alberto Guerreiro Ramos}

Pontos de intersecção podem ser observados no pensamento de Cornelius Castoriadis e Alberto Guerreiros Ramos. Um desses pontos está na análise das funções do mercado.

A afirmativa de que o mercado não é, nunca foi e jamais será, por mais duradouro que seja o sistema capitalista, um mercado "perfeito" nem verdadeiramente concorrencial, no sentido atribuído pelos manuais de economia política, permite inferir do autor que a mão invisível que promoveria seu equilíbrio, defendida pelos clássicos, de fato não se efetiva. Ao analisar a crise do desenvolvimento, ressalta que ela é também a crise dos "postulados" (homo economicus, a "mão invisível", o liberalismo e as virtudes da livre concorrência). Acrescenta que o mercado pouco difere de uma selva moderadamente selvagem e, como em toda selva, os mais aptos a sobreviver sobrevivem (CASTORIADIS, 1996; 1987b).

Ramos (1981) enfatiza a intransigente defesa do livre mercado pelo pensamento clássico, com o suposto equilíbrio entre a oferta e a procura de bens. O mercado alcança esse equilíbrio por meio de uma "mão invisível" que o regula, tornando possível o atendimento dos diversos interesses. O autor critica tal assertiva e afirma que Adam Smith agiu como fundamentalista ao exaltar o mercado como um ethos da existência humana. Para ele, o mercado não deve funcionar em bases puramente técnicas e econômicas, constituindo apenas um enclave do sistema social.

Na perda da auto-orientação, um outro ponto em comum. Em Ramos (1981, p. 52) "O indivíduo ganhou melhoria material em sua vida e pagou por ela com a perda do seu senso pessoal de auto-orientação". Em Castoriadis (2002) a autonomia, que corresponde ao indivíduo crítico, reflexivo, democrático, está atravessando uma fase de eclipse ou de ocultação prolongada, ao mesmo tempo que o conflito sociopolítico praticamente desaparece. A mitologia do progresso está caindo em ruínas. A única significação que verdadeiramente existe e domina é a significação capitalista. A expansão do domínio é percebida por alguns. Mas para a esmagadora maioria isso não é e não pode ser senão um aumento contínuo do consumo de bens, incluindo os pretensos lazeres, que se tornaram um fim em si mesmos. Cria-se então um modelo de indivíduo que ganha o máximo possível e usufrui o máximo. É assim, simples e banal. Ganhar é agora algo quase totalmente separado que qualquer função social e mesmo de qualquer legitimação interna do sistema.

O pensamento sobre economia também aproxima Castoriadis e Ramos. A economia é criticada por Castoriadis (1987b) por ser o reino e paradigma da "racionalidade" e previsibilidade nos assuntos humanos. Os fenômenos econômicos parecem prestar-se a um tratamento exato, que pode ser realizado pela aplicação de instrumental matemático, ou seja, a supremacia do cálculo econômico. A esse respeito, Ramos (1981) afirma que o conceito de racionalidade predominante na teoria organizacional vigente parece afetado por fortes implicações ideológicas, levando a considerar que o comportamento econômico constitui a totalidade da natureza humana, além de assegurar a existência de um esforço histórico para modelar a ordem social de acordo com critérios de economicidade.

O último dos pontos analisados refere-se ao modelo de desenvolvimento. Assinala Castoriadis (1987b) que é preciso denunciar e destruir a ideologia racionalista, a ilusão da onipotência, a supremacia do "cálculo" econômico, o caráter absurdo e incoerente da organização "racional" da sociedade, a nova religião da "ciência", a ideia do desenvolvimento pelo desenvolvimento. Ramos (1981) corrobora tal preocupação e critica o operacionalismo positivista - um operacionalismo que só admite existir sabedoria em critérios de exatidão, ou seja, virtude moral e beleza estética não são dados à percepção humana como o são o tamanho, a forma, a extensão e a quantidade de objetos. Na raiz do operacionalismo está o interesse em lidar com os problemas práticos do mundo. O operacionalismo positivista é permeado por uma orientação controladora de mundo. 


\section{Pontos de divergência entre Cornelius Castoriadis e Alberto Guerreiro Ramos}

A questão que separa os dois autores está no sentido atribuído à razão e em sua instância de domínio.

Ramos (1981) compartilha do conceito de razão oriundo de seu sentido clássico. A razão era entendida como força ativa na psique humana que habilitava o indivíduo a distinguir entre o bem e o mal, entre o conhecimento falso e o verdadeiro, e assim ordenar sua vida pessoal e social. Mais ainda, a existência da razão na psique humana era encarada como uma realidade que possibilitava ao indivíduo resistir a sua redução a fenômeno histórico e social. Ramos acrescenta que todas as sociedades são menos do que boas; apenas o ser humano eventualmente merece ser caracterizado como bom. Essa concepção decorre do pensamento de que todos os homens são guiados em qualquer momento e em qualquer lugar por uma razão substantiva que não deve ser considerada coincidente com padrões particulares de qualquer sociedade determinada. A racionalidade, no sentido substantivo, nunca poderá ser um atributo definitivo da sociedade, pois é diretamente apreendida pela consciência humana, não pela mediação social. A razão pode ser assim compreendida como uma virtude do indivíduo, e não uma característica da sociedade.

Ao falar sobre a concepção weberiana de razão, Ramos (1981) assegura que Weber viveu o contexto histórico em que a racionalidade funcional ou formal substituía a racionalidade substantiva. Porém, Weber tomou como certa essa substituição sem problematizar a questão da racionalidade substantiva no campo das ciências. Já Karl Mannheim foi criticado pelo ecletismo de suas posições.

A razão, para Castoriadis (1999a), não está no indivíduo. Os indivíduos socializados são, antes, fragmentos ambulantes e falantes de uma sociedade dada. O indivíduo é uma criação social. As sociedades são sempre históricas não produtíveis causalmente nem dedutíveis racionalmente. As instituições e a significações imaginárias sociais de cada sociedade são criações livres e imotivadas do coletivo anônimo. A compreensão é nosso modo de acesso ao mundo, e ela não passa essencialmente pela referência ao indivíduo. Mas, acrescenta, o objeto social-histórico é co-constituído pelas atividades dos indivíduos, que encarnam ou realizam concretamente a sociedade em que vivem. O indivíduo nada mais é do que a sociedade (CASTORIADIS, 1992 a).

Castoriadis (1992a) ratifica que a unidade profunda da razão se manifesta numa diversidade fenomenal, daí a dificuldade de explicar como ordená-la racionalmente. A razão é, nesse sentido, resultado do social-histórico. O autor assegura que os fenômenos social-históricos são irredutíveis a um agir individual, coerência, além do funcional, de toda sociedade em matéria de sentido, irredutibilidade das formações social-históricas de uma às outras, e de todas a uma progressão da razão. A razão está presente em um coletivo social anônimo, e não em indivíduos substanciais, embora se apoie em possibilidades e tendências intrínsecas da psique humana (CASTORIADIS, 1999a).

Ao admitir a ideia de racionalidade instrumental em Weber, Castoriadis (1992a) adverte, todavia, que a socialização dos indivíduos, processo ele próprio socialmente instituído, abre acesso a um mundo de significações imaginárias sociais. E essas significações não são redutíveis à "racionalidade", qualquer que seja a extensão dada ao sentido do termo. A compreensão do mundo social-histórico não se reduz à reconstituição de alguns fragmentos ou dimensões instrumentalmente racionais do agir.

\section{Considerações finais}

Uma leitura dos temas precedentes nas obras de Cornelius Castoriadis e de Guerreiro Ramos sugere a influência predominante dos filósofos gregos e do pensamento weberiano sobre as ideias desses dois autores. $\mathrm{Na}$ essência desses temas, constata-se um ponto central de divergência e outros de aproximação. O primeiro refere-se ao contexto de domínio da razão, enquanto os demais tratam da autonomia, da liberdade relativa aos sujeitos e das formações sociais, relacionados a pressupostos de desenvolvimento e de consumo da 
sociedade moderna. A compreensão subjacente a essas concepções permite afirmar que elas se complementam na medida em que contribuem para o entendimento dos povos e dos indivíduos nos contextos de convivência macrossociais e nos ambientes organizacionais.

Em Guerreiro Ramos, a preocupação com a razão dominante que orienta relações, liberdade, autonomia, existência substantiva, manifesta-se na visão do autor sobre as relações indivíduo-sociedade e indivíduoorganização, que, permeadas por critérios de utilidade, não contribuem para a existência e para a escolha de vida substantiva. A sociedade assim compreendida não gera padrões de existência substantiva em seu conjunto, enquanto, no que diz respeito à relação indivíduo-organização, afirma Ramos (1983) que as organizações são abstrações, são fantasmas; de concreto, somente as pessoas que por elas agem e respondem. Imperativos que assegurem a existência social das organizações e a existência substantiva dos indivíduos são o que se espera de uma ação administrativa. A razão em seu sentido substantivo, atributo do indivíduo, é a força modeladora da ética e da escolha existencial substantiva. Adicionalmente, as opções de existência não devem limitar-se a vínculos com as organizações formais. Nessa perspectiva, fora do paradigma econômico existe alternativa de trabalho e opção de vida substantiva. Essa visão é complementada pelo teor críticosociológico de Ramos (1996), segundo o qual o modelo de desenvolvimento das nações centrais não pode ser transplantado para as nações periféricas. Há que se considerar fatores como as especificidades dos povos, além da formação econômica e cultural e os valores cultivados pela nação. Não existe uma solução universal para os problemas das nações.

Em uma outra perspectiva, Castoriadis (1992a; 1999b) compartilha da ideia de que, quer se trate de atos individuais, fenômenos coletivos, artefatos ou instituições, o objeto é colocado no horizonte da perspectiva social-histórica. A razão é resultado do social-histórico e irredutível a um agir individual. O objeto socialhistórico é co-constituído pelas atividades dos indivíduos, que encarnam ou realizam concretamente a sociedade em que vivem. O indivíduo nada mais é do que a sociedade. A sociedade é autocriação. As significações sociais fazem parte da forma de ser da própria sociedade. A sociedade resulta das contribuições de um "coletivo anônimo". O homem e a sociedade são inseparáveis de seu contexto - o contexto socialhistórico.

Essa diferente perspectiva de razão em Castoriadis serve de balizamento para sua obstinada defesa da liberdade, democracia e autonomia dos povos e das nações. Reconhecendo a importância da alteridade e a predominância da antinomia, propõe um resgate das significações imaginárias sociais como forma de restabelecer a harmonia e o equilíbrio, sem predomínio de civilizações ou culturas. Para Castoriadis, tempo é criação. Isso implica afirmar que os valores, as normas, as técnicas e as formas de vida de um povo ou de nações são livres escolhas que decorrem de determinado momento histórico.

Infere-se, ainda, em Castoriadis, que não há espaço para uma retórica do desenvolvimento universal. Subjacente a essa visão, o autor sugere que não existe uma teoria capaz de explicar plenamente o comportamento dos indivíduos no contexto organizacional, uma vez que a psique resiste ao processo de socialização e apenas parcialmente subordina suas criações e seus impulsos às exigências da vida social. Assinala, ainda, que as significações imaginárias, específicas de cada contexto, de cada povo e de cada nação, constituem a forma de ser desses povos e nações e o modo como se veem e se interpretam.

As ideias de Guerreiro Ramos e Castoriadis revelam-se um avanço no campo analítico social e teóricoorganizacional. Ao se posicionar criticamente, Guerreiro Ramos denunciou as ciências sociais e, em particular, a teoria das organizações pelo pragmatismo e vinculação a alicerces epistemológicos que têm como sustentação a sociedade centrada no mercado. Uma ciência e uma teoria assim constituídas somente poderiam inspirar nos indivíduos um cálculo utilitário de consequências, em detrimento de padrões de existência substantiva e convivência social harmônica. Adotados pela ciência social e, em particular, pela teoria da organização, esses pressupostos distorcem o verdadeiro sentido da razão e afetam profundamente as ações e as condutas individuais. 
Também os padrões de desenvolvimento são permeados por critérios de economicidade, originados do mercado e incorporados acriticamente pela teoria das organizações. Defende Guerreiro Ramos a necessidade de uma "nova ciência das organizações", crítica, que inspire novos modelos de organização e que permita a seus agentes a opção pela existência substantiva, e na qual os negócios humanos comuns não sejam permeados pelos traços subjacentes à sociedade centrada no mercado. Com uma concepção antropológica, defende uma Sociologia histórica, própria aos países em desenvolvimento, e abre caminho para a perspectiva crítica da teoria administrativa.

A contribuição e a perspectiva crítica de Castoriadis não são menores. $\mathrm{O}$ autor tece profundas críticas à Filosofia, responsabilizando-a por ter ignorado o social-histórico, tanto como domínio próprio como modo de ser; a Ontologia, pelo caráter determinista de sua orientação; e a Economia, por tentar se constituir no reino e paradigma de certeza e previsibilidade dos assuntos humanos. É, pois, recorrente no autor a crítica às ciências sociais, por ter se tornado instrumento de distorção, de dominação e de defesa de um desenvolvimento universal irreversível e inconsequente, bem como a crítica ao caráter utilitário e ao consumismo desenfreado que caracterizam as sociedades "desenvolvidas".

Da complexidade do processo de socialização, do caráter social-histórico que atribui às relações indivíduosociedade e da compreensão sobre a transitoriedade, o dinamismo e a relatividade das normas que regem as condutas sociais e humanas decorre o pensamento do autor de que as nações e os indivíduos se encontram sob a permanente pressão do instituído e do instituinte social e organizacional.

Ao ponderar sobre os conhecimentos acumulados pelas ciências, Castoriadis (1987b) ressalta que esses conhecimentos podem ajudar a sociedade na medida em que contribuam para denunciar e destruir a ideologia racionalista, a ilusão da onipotência, a supremacia do "cálculo", a organização "racional" da sociedade e a ideia de desenvolvimento pelo desenvolvimento. Isso só se concretizará se formos capazes de reconhecer a razão e a responsabilidade como criações históricas do homem.

As percepções desses autores sugerem um rompimento com o domínio lógico-metodológico quantitativo, característico do positivismo iluminista, uma vez que em suas concepções críticas ressaltam o caráter pragmático e dominante das ciências sociais. Ao negarem os pressupostos de uma ciência social universal, abrem espaço para análises qualitativas no âmbito dos estudos sociais e organizacionais.

Pode-se afirmar que, com uma relativa unicidade de pensamento e de proposição positivista dominante, os autores se distinguiram em suas contribuições teóricas por retratar de forma mais realista a natureza e a complexidade das relações que predominam nos contextos de ações sociais e humanas, defendendo com intransigência realidades locais e leituras mais fiéis das situações vivenciadas pelos indivíduos e as sociedades.

Alves (2007) também contribui para elucidar as diferenças e convergências entre Ramos e Castoriadis. Afirma que é difícil fazer ciência rigorosa no mundo humano. O problema não está nem nas teorias, nem nos métodos, mas na própria natureza do objeto. Um indivíduo é um ser único. Sobre ele não se pode fazer ciência. Mas o fato é que todos os indivíduos estão situados em certas entidades sociais, que são sociais exatamente por serem comuns e universais.

\section{Referências}

ALVES, R. A filosofia da ciência: introdução ao jogo e suas regras. 13. ed. São Paulo: Loyola, 2007.

BRESSER-PEREIRA, L. C. A organização burocrática. In: PEREIRA, L. C. B.; MOTTA, F.C. P. (Orgs.). Introdução à organização burocrática. 7. ed. São Paulo: Brasiliense, 1991. 
CASTORIADIS, C. O imaginário: a criação no domínio social-histórico. In: PEREIRA, L. C. B.; MOTTA, F.C. P. (Orgs.). Os domínios do homem: encruzilhadas do labirinto II. São Paulo: Paz e Terra, 1987a.

Reflexões sobre o "desenvolvimento" e a "racionalidade”. In: PEREIRA, L. C. B.; MOTTA, F.C. P. (Orgs.). Os domínios do homem: encruzilhadas do labirinto II. São Paulo: Paz e Terra, 1987b.

Indivíduo, sociedade, racionalidade, História. In: PEREIRA, L. C. B.; MOTTA, F.C. P. (Orgs.). O mundo fragmentado: as encruzilhadas do labirinto III. Rio de Janeiro: Paz e Terra, 1992a.

. Tempo e criação. In: PEREIRA, L. C. B.; MOTTA, F.C. P. (Orgs.). O mundo fragmentado: as encruzilhadas do labirinto III. Rio de Janeiro: Paz e Terra, 1992b.

. A racionalidade do capitalismo. Conferência pronunciada no Colóquio CIRFIP "Racionalidade Instrumental e Sociedade", 1996.

Feito e a ser feito: trajetória de uma filosofia da emancipação. In: PEREIRA, L. C. B.; MOTTA, F.C. P. (Orgs.). Feito e a ser feito: as encruzilhadas do labirinto V. Rio de Janeiro: DP\&A, 1999a.

Imaginação, imaginário, reflexão. In: PEREIRA, L. C. B.; MOTTA, F.C. P. (Orgs.). Feito e a ser feito: as encruzilhadas do labirinto V. Rio de Janeiro: DP\&A, 1999 b.

A crise do processo de identificação. In: PEREIRA, L. C. B.; MOTTA, F.C. P. (Orgs.). A ascensão da insignificância: as encruzilhadas do labirinto IV. Rio de Janeiro, Paz e Terra, 2002.

POSFÁCIO. In: PEREIRA, L. C. B.; MOTTA, F.C. P. (Orgs.). Sujeito e verdade no mundo social histórico. Rio de Janeiro: Civilização Brasileira, 2007.

RAMOS, A. G. A nova ciência das organizações: uma reconceituação da riqueza das nações. Rio de Janeiro: FGV, 1981.

. Administração e contexto brasileiro: esboço de uma teoria geral da administração. 2. ed. Rio de Janeiro: FGV, 1983.

A redução sociológica. 3. ed. Rio de Janeiro: UFRJ, 1996. 